\title{
Annals of the Rheumatic Diseases
}

\section{Leader}

\section{How should we manage fibromyalgia?}

There are rheumatologists who might prefer the title of this editorial to be abbreviated to: "Should we manage fibromyalgia?" Or changed to "What is to be done about fibromyalgia?" When you attend regional, national, and even international meetings it seems that interest in fibromyalgia among rheumatologists is increasing, commensurate with a decline in enthusiasm for actually managing patients with the syndrome. Such has been the success of those who preached the gospel of fibromyalgia, who proselytised to the doubting Thomases over the past two decades, that to harbour, let alone express, reservations is regarded as heresy. I would not admit to having had a "road to Damascus" conversion to disbelief, but I do agree with others that a rethink is necessary. ${ }^{1-3}$ That the diagnosis has gained credibility cannot be doubted. Fibromyalgia is now a familiar concept and diagnosis among general practitioners, physiotherapists, general physicians, and even (heaven help us) some orthopaedic surgeons. Patients may request or demand a specialist consultation after self diagnosis, and often come clutching pages of information downloaded from the internet. The self help movement has an apparently unstoppable momentum, especially in North America. In fibromyalgia, we may have created a monster. Is it now clinically, socially, and financially appropriate to slay that monster? ${ }^{1}$

Even Dr Fred Wolfe, who has done so much quality research into fibromyalgia and published so prolifically, is entertaining second thoughts. ${ }^{2}$ These have arisen because in North America, and increasingly so in the United Kingdom, the concept of fibromyalgia is being highjacked by lawyers. Those who satisfy the 1990 ACR Classification criteria are being accepted as permanently disabled, and are receiving workers compensation, personal injury payouts, and early retirement pensions. ${ }^{34}$ These criteria were surely not designed to legitimise a purely subjective disorder of chronic pain and perceived disability, with examination findings being only semi-objective at most? Surely invalidity benefits were introduced to provide a financial safety net for those with physical diseases and structural pathology, rather than psychosomatic, stress related illnesses? ${ }^{5}$ And yet those involved in medicolegal work are seeing increasing numbers of plaintiffs with functional, diffuse pain problems, but no structural pathology, and the basis of the claim is fibromyalgia. Often the index event involves distressing but minor physical trauma, and the chronicity and severity of subsequent pain and disability often seem to be inversely proportional to the severity of the initial damage. Indeed, perhaps like the clinically similar "repetitive strain injury", there is a possible major iatrogenic input to the plaintiffs' chronic illness. ${ }^{6}$ The superficially respectable, but pseudoscientific, label of "fibromyalgia" may be interpreted by both patient and lawyers as providing an official medical stamp of approval for failing to cope with the consequences of minor road traffic accidents, tripping over loose kerbstones, or having a stressful occupational or domestic environment. "Posttraumatic fibromyalgia" still flourishes in legal circles even if the term may have been discouraged in the journals. ${ }^{7}$

What then to do when referred a patient with possible fibromyalgia? It is as well to assign a slightly longer appointment than for other conditions, perhaps 45 minutes rather than the 30 minutes often put aside even for new cases of rheumatoid arthritis or system lupus erythematosus. Document carefully, and without pre-judgement, the many symptoms of which the patient will complain. Enquire after stressful life events, both physical and emotional, that might impact on subsequent ability to cope with pain or other stressor. Ask if the patient has a pet theory about why they have reached such a state. There may be scientifically and pathologically untenable beliefs, or unjustified anxieties amenable to cognitive therapy. Examine for possible thyroid disease, inflammatory or degenerative arthritis, polymyalgia and polymyositis, and connective tissue disease. Statistically the chances are very high that there will be no serious underlying disease, that typical features of fibromyalgia will allow for a positive diagnosis, and not one of exclusion. A careful history and sympathetic, competent and thorough examination by a physician familiar with the concept of fibromyalgia may prevent the patient seeking yet another opinion. Arrange laboratory and radiological assessments with equal care, as an investigational "fishing expedition" may merely serve to reinforce bizarre beliefs and abnormal illness behaviour. A full explanation about the complex and multifactorial nature of chronic pain should follow, flagging up physical inputs such as lack of physical fitness, poor posture, or joint hypermobility (not at all uncommon), ${ }^{8}$ as well as possible emotional inputs, such as interpersonal stress, unresolved guilt or grief or anger. Allude to the vicious cycle of poor sleep, fatigue, disinclination for exercise, anxiety and pain. Indicate where the cycle might be broken for that person and what sort of exercise they might take up. I strongly recommend water aerobics, line dancing, t'ai chi, yoga, then some light work in a gymnasium. Although electro- 
therapy is rarely beneficial, a physiotherapist with a particular interest in sports medicine can suggest an appropriate exercise regimen tailored to a person. The programme should be "goal orientated", and the goalposts should be shifted as goals are achieved. Offer professional dietary assessment and advice for those who are obese. Discourage the use of stimulants such as caffeine, alcohol, and tobacco, especially in the evenings. Preach the philosophy of a healthy mind in a healthy body, of there being no gain without pain, of pushing against the pain barrier so that it moves progressively further away. Explain that getting fit is a tiring, painful process, even for those without fibromyalgia. For those with poor sleep and low mood I suggest the combination of tricyclic agent taken in low dose an hour or two before bedtime, plus a morning dose of an SSRI antidepressant drug. My own experience is that nocturnal dothiepin is better tolerated than amitryptylline. The patient should be told that the aim is to modify neuropeptides important for regulating pain, sleep, and mood. Overall, the physician must use the power of his own status and personality to motivate the patient to change their beliefs and behaviour, and to play the dominant part in their own return to health.

Reaching for the prescription pad is sometimes a mark of desperation, a signal that the consultation is over. We know that simple and anti-inflammatory analgesics are not very effective ${ }^{910}$ and that corticosteroids don't work. ${ }^{11}$ A role for the synthetic opioid tramadol has been suggested, and intravenously at that. ${ }^{12}$ It seems unlikely that such treatment will prove appropriate in such a chronic condition as fibromyalgia. Of interest, pain reduction was not associated with reduced tender point sensitivity. Subnormal growth hormone secretion, as assessed by serum concentrations of somatomedin-C, has been demonstrated in some fibromyalgia patients. ${ }^{13}{ }^{14}$ Bennett's group have recently reported symptomatic improvement after nine months of daily subcutaneous injection of growth hormone. ${ }^{15} \mathrm{I}$ am old old enough to remember the "Bovril stimulation test" in children with suspected pituitary failure and growth hormone deficiency. This preparation has the consistency of yellow soft paraffin, and is a form of beef extract used in Britain to make hot drinks, but can also be spread on sandwiches. The Australian equivalent, Vegemite, is a yeast extract with similar appearance and taste. Perhaps a cheaper and more convenient treatment to that reported by Bennett would be daily Bovril or Vegemite sandwiches! Reassuringly, or perhaps disappointingly, alternative/complementary practitioners find fibromyalgia equally difficult to manage. ${ }^{16} \mathrm{~A}$ comprehensive pain management programme, where available, has perhaps the best chance of success, ${ }^{17}$ although even rheumatologists can practise amateur cognitivebehavioural therapy in the clinic.

Should patients with fibromyalgia be given some of the increasing number of available information leaflets about the syndrome, or encouraged to join a patient self help group? In the clinically similar chronic fatigue syndrome, joining such a group has been linked to a worse prognosis. ${ }^{18}$ Some patients may read or hear about symptoms experienced by others and subconsciously incorporate them into their own syndrome. I prefer to give information about how to manage chronic pain in general rather than fibromyalgia in particular. Should patients be offered a review appointment? It is rare when dealing with other complex chronic musculoskeletal disorders not to review the patient at least once, to evaluate the accuracy of diag- nosis or the outcome of a management stratagy, and it seems unfair not to do likewise with fibromyalgia. I offer another appointment on the understanding that I will not re-record all the patient's symptoms, but will note down all the positive steps he or she has taken to ameliorate them: how much weight has been lost, how many lengths are being swum and how often, what stress management techniques are being practised? Those who still think their fibromyalgia is my problem alone are swiftly disabused of the notion.

And what of those who have used the consultation as a prelude to litigation? The long course of disputes encouraged by an adversarial legal system means that the patient/ plaintiff cannot recover lest they jeopardise their case. Ongoing litigation acts as a powerful disincentive to successful rehabilitation, and this can be either premeditated or, more usually, entirely subconscious. Pain and pain behaviour may become ingrained, and be irremediable. As to prognosis, this is generally accepted as being poor, ${ }^{19}{ }^{20}$ but not in all published series. ${ }^{21}$ The approach to management I recommend is stressful and exhausting, and sometimes even successful. Perhaps prognosis is partly related to how much effort is made to confront the issues. If the patient leaves the consultation with motivation and optimism for their future, then entropy dictates that this positive energy has not been created, but merely transferred, redistributed from the physician. Amen, here endeth the lesson.

Frimley Park NHS Trust Hospital, Portsmouth Road, Frimley,

PAUL A REILLY Camberley, Surrey, GU16 5UF

1 Carette S. Fibromyalgia 20 years later: what have we really accomplished? J Rheumatol 1995;22:590-2.

2 Wolfe F. The fibromyalgia problem. J Rheumatol 1997;24:1247-9.

3 Hadler N. Fibromyalgia: La maladie est morte. Vive le Malade! J Rheumatol 1997;24:1250-1.

4 Bennett RM. Disabling fibromyalgia: Appearance versus reality. J Rheumatol 1993;20:1821-4.

5 Hadler N. Workers' compensation and chronic regional musculoskeletal pain. Br J Rheumatol 1998;37:815-18.

pain. Br J Rheumatol "RSI": a model of social iatrogenesis. Med J Aust 1987;147:236-9.

7 Wolfe F, Allen M, Bennett RM, Bombardier C, Broadhurst N, Cameron RS, et al. The Fibromyalgia Syndrome: a consensus report on fibromyalgia and disability. J Rheumatol 1996;23:534-9.

8 Acasuso-Diaz M, Collantes-Estevez E. Joint hypermobility in patients with fibromyalgia syndrome. Arthritis Care and Research 1998;11:39-42.

9 Yunus MB, Masi AT, Aldag JC. Short term effects of ibuprofen in primary fibromyalgia syndrome: a double blind, placebo controlled trial. J Rheumatol 1989;16:527-32.

10 Goldenberg DL, Felson DT, Dinerman H. A randomized, controlled trial of amitriptylline and naproxen in the treatment of patients with fibromyalgia. Arthritis Rheum 1986;29:1371-7.

11 Clark S, Tindall E, Bennett RM. A double blind crossover trial of prednisone versus placebo in the treatment of fibrositis. J Rheumatol 1985; 12:980-3.

12 Biasi G, Manca S, Manganelli S, Marcolongo R. Tramadol in the fibromyalgia syndrome: a controlled clinical trial versus placebo. Int J Clin Pharmacol Res 1998;18:13-19.

13 Bagge E, Bengtsson B-A, Carlsson L, Carlsson J. Low growth hormone secretion in patients with fibromyalgia- a preliminary report on 10 patients and 10 controls. J Rheumatol 1998;25:145-8.

14 Bennett RM, Cook DM, Clark SR, Burckhardt CS, Campbell SM Hypothalamic-pituitary-insulin-like growth factor-1 axis dysfunction in patients with fibromyalgia. J Rheumatol 1997;24:1384-9.

15 Bennett RM, Clark SC, Walczyk J. A randomized, double-blind, placebo-controlled study of growth hormone in the treatment of fibromyalplacebo-controlled study of growt
gia. Am J Med 1998;104:227-31.

16 Fitzcharles M-A, Esdaile JM. Nonphysician practitioner treatments and fibromyalgia syndrome. J Rheumatol 1997;24:937-40.

17 Mason LW, Goolkasian P, McCain GA. Evaluation of a multimodal treatment program for fibromyalgia. J Behav Med 1998;21:163-78.

18 Sharpe M, Hawton K, Seagroatt V, Pasvol G. Folloe-up of patients presenting with fatigue to an infectious diseases clinic. BMJ 1992;305:147-52.

19 Felson DT, Goldenberg DL. The natural history of fibromyalgia. Arthritis Rheum 1986;29:1522-6.

20 Ledingham J, Doherty S, Doherty M. Primary fibromyalgia syndrome- an outcome study. Br J Rheumatol 1993;32:139-42.

21 Granges G, Zilko P, Littlejohn GO. Fibromyalgia syndrome: assessment of the severity of the condition 2 years after diagnosis. J Rheumatol 1994;21: 523-9. 